\title{
Characterization of the High Molecular Weight Cd-Binding Complex in Water Hyacinth (Eichhornia crassipes) When Exposed to Cd
}

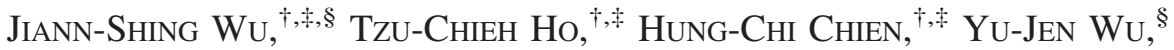 \\ ShyH-Mirn Lin," AND Rong-Huay JuAnG*,* \\ Department of Biochemical Science and Technology and Institute of Microbiology and Biochemistry, \\ National Taiwan University, Taipei, Taiwan 106, Department of Beauty Science, Meiho Institute of \\ Technology, Pingtung, Taiwan 912, and Department of Food Nutrition, Chung Hwa University of \\ Medical Technology, Tainan, Taiwan 717
}

\begin{abstract}
Water hyacinth (Eichhornia crassipes) is a rapid-growing freshwater vascular plant that has been used to remove heavy metals in contaminated water. But the transportation and distribution of the absorbed heavy metal in the plant are not clear. In this study, water hyacinth was exposed to cadmium ( $\mathrm{Cd}, 10 \mu \mathrm{M}$, pulse) and then transferred to a Cd-free solution (chase). The Cd content in the tissues was measured, and the Cd-binding complexes were isolated and identified. We found that (1) in two days, up to $80 \%$ of the $\mathrm{Cd}$ in the solution was absorbed by the plant, and the Cd could not be released back to the growth solution in the chase period; (2) approximately $1 \mathrm{mg}$ of $\mathrm{Cd}$ was accumulated in the water hyacinth/g of dry weight in this condition; (3) invading Cd was bound rapidly as the lowmolecular-weight (LMW) complex serving as the transient form for further sequestration; (4) the LMW complex in water hyacinth contained no phytochelatins and was different from the LMW complex in fission yeast; (5) the Cd absorbed in the plant was essentially stored in the high-molecular-weight (HMW) form after 1 week; (6) a small fraction of the absorbed Cd was found in the upper part of the plant (stem and leaves) in the form of complexes; (7) the HMW complex was composed of phytochelatins $\mathrm{PC}_{3}$ and $\mathrm{PC}_{4}$ primarily, with only a small amount of $\mathrm{PC}_{2} ;(8)$ a rare $\mathrm{PC}$-related peptide was found in the HMW complex that might be derived from $\mathrm{PC}_{3}$. These observations contribute to the further understanding of water hyacinth in serving as an efficient and reliable accumulator for heavy metals.
\end{abstract}

\section{KEYWORDS: Cd-binding complex; Eichhornia crassipes; phytochelatin; water hyacinth}

\section{INTRODUCTION}

Cadmium $(\mathrm{Cd})$ is one of the transition metals with incompletely filled $\mathrm{d}$ orbitals, which could form stable compounds with the metabolites or proteins in the cell. This binding capacity along with heavy industry pollution has made $\mathrm{Cd}$ one of the most dangerous environmental threats to living organisms. Facing the invading $\mathrm{Cd}$, cells basically produce defensive compounds that can bind to $\mathrm{Cd}$ immediately and form a harmless complex that can be sequestered safely. These Cd-binding compounds include metallothionein, a family of small proteins containing repeats of the Cys-Cys motif $(1,2)$, and the phytochelatins (PCs), which are short isopeptides found in fission yeast (3) or plant

\footnotetext{
* Corresponding author: tel 886-2-2363-1704; e-mail juang@ ntu.edu.tw.

${ }^{\dagger}$ These authors contributed equally to this work.

* National Taiwan University.

$\S$ Meiho Institute of Technology.

"Chung Hwa University of Medical Technology.
}

cells $(4,5)$. PCs have the general structure ( $\gamma$ Glu-Cys $)_{n}$-Gly $(n=2-11)$, which could bind with $\mathrm{Cd}$ and produce two major complex forms. In fission yeast, a low-molecularweight complex (LMW) is formed first, which contains several Cd atoms bound by shorter PCs (essentially $\mathrm{PC}_{2}$ and $\mathrm{PC}_{3}$ ). The LMW complex is then transported into the vacuole for storage through a transporter on the membrane (6). During this process, the $\mathrm{Cd}$ is incorporated with sulfide as $\mathrm{CdS}$, and the complex is rearranged to accommodate longer PCs (essentially $\mathrm{PC}_{3}$ and $\mathrm{PC}_{4}$ ), and a stable high-molecular-weight (HMW) complex is produced $(7,8)$. It was proposed that cysteine sulfinate is the substrate in the purine biosynthesis pathway to supply the sulfide in the HMW complex (9). PCs are not translational products; instead they are synthesized by the enzyme phytochelatin synthase (PCS), which has been studied extensively in terms of molecular genetics, as well as enzyme catalytic mechanism, in the past decade $(1,10-12)$. Besides the heavy-metal binding peptides, plants also produce antioxidants as an efficient way to protect themselves (13). 
A
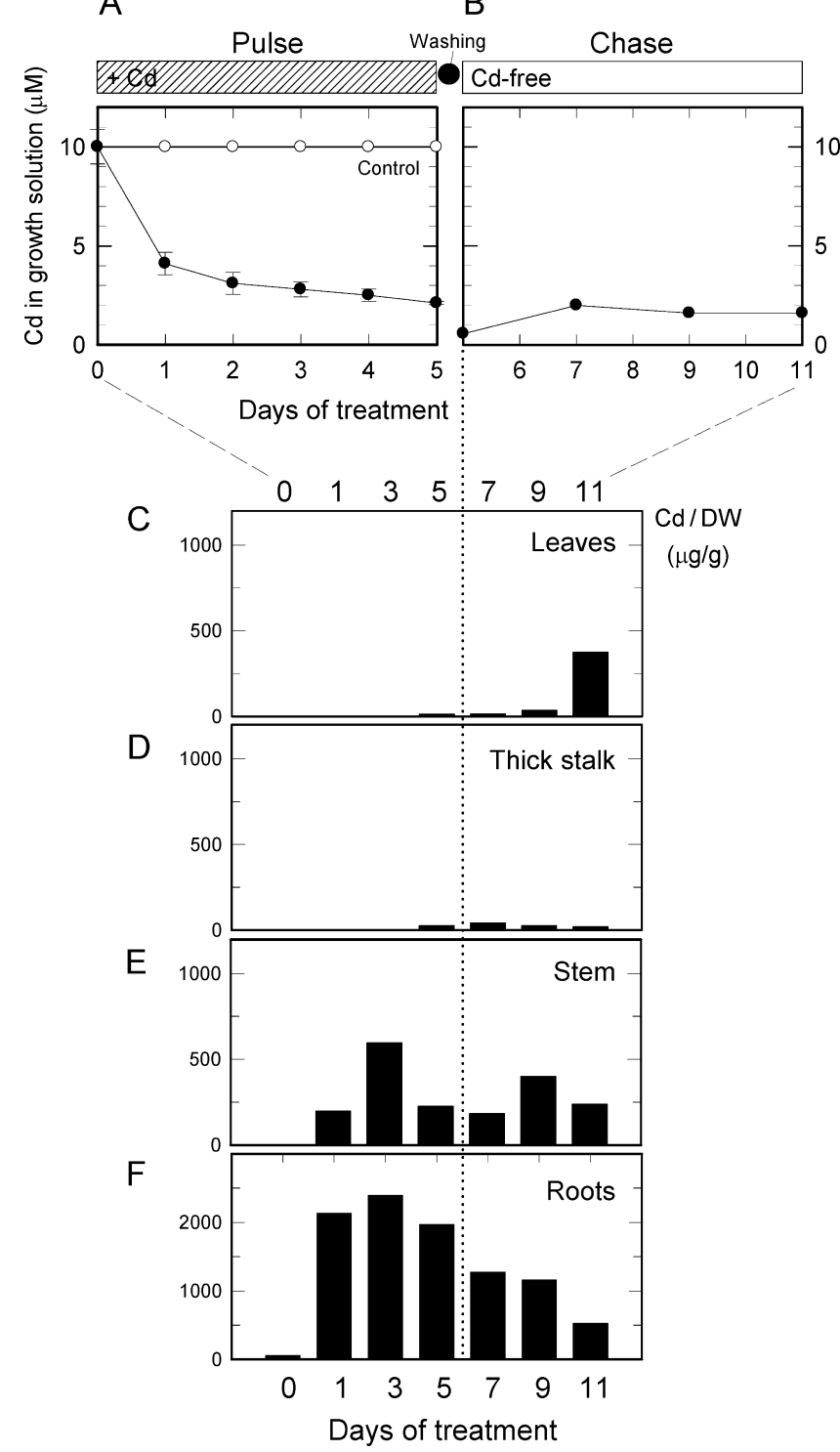

Figure 1. (A) Water hyacinth was grown in a solution containing $\mathrm{Cd}(10$ $\mu \mathrm{M}$ ) for 5 days (pulse period), the plant was washed and then transferred to the fresh growth solution free of exogenous $\mathrm{Cd}(\mathbf{B}$, chase period). The $\mathrm{Cd}$ contents in the growth solution during this pulse-chase treatment were monitored. Control in the pulse period was performed in which none of the plants were cultivated in the growth solution. Water hyacinth tissues were collected during the pulse-chase treatment of $\mathrm{Cd}$ and separated into leaves $(\mathbf{C})$, thick stalk $(\mathbf{D})$, stem $(\mathbf{E})$, and roots $(\mathbf{F})$. The $\mathrm{Cd}$ content and dry weight of each sample were measured to show the change of $\mathrm{Cd}$ accumulation in plant tissues. DW, dry weight of the plant. Representative data are shown $(n=2)$.

Phytoremediation is an environmentally friendly process for recovering contaminated areas in the presence of heavy metal. Many plants are hyperaccumulators of toxic metals and have been utilized extensively in the remediation of metal-contaminated soils (14). On the other hand, contamination in rivers and lakes by industrial waste might be worse, and various aquatic plants are exploited for the same purpose. Water hyacinth is a plant that floats on water with a large, freely hanging root system, and it is notorious for its invasive growing rate (15). However, it is highly resistant to toxic environments and has been used for the treatment of wastewater (15) and the sequestration of heavy metals $(16,17)$. Two decades ago, Fujita examined the Cd-binding substances in water hyacinth (18) and concluded that these substances comprised cadystin (19) which were known as phytochelatin in the plant (4). This research contributed to the basic understanding of the Cd-binding complexes in water hyacinth; however, detailed properties and distribution of these complexes are still lacking.

In this study, we monitored the dynamic distribution of $\mathrm{Cd}$ when absorbed into the plant body. In order to trace $\mathrm{Cd}$ in a clear background, a "pulse and chase" mode was used in which water hyacinth was exposed to $\mathrm{Cd}$ for 5 days (pulse) and then changed to a Cd-free environment (chase). During these stages, the $\mathrm{Cd}$ and its complexes with PCs were analyzed in different tissues to reveal their dynamic distribution. The component of HMW complex was further explored, and a rare derivative of phytochelatin was found.

\section{MATERIALS AND METHODS}

Water hyacinth (Eichhornia crassipes) was obtained from a local farm near Taipei. The plant was grown at room temperature $(24 \sim 30$ ${ }^{\circ} \mathrm{C}$ ) in a plastic cylindrical pot (inner diameter $19 \mathrm{~cm}$, height $23 \mathrm{~cm}$ ) containing $5 \mathrm{~L}$ of the growth solution $\left(\mathrm{NaNO}_{3}, 1.7 \mathrm{mM} ; \mathrm{CaCl}_{2}, 170\right.$ $\mu \mathrm{M} ; \mathrm{KH}_{2} \mathrm{PO}_{4}, 180 \mu \mathrm{M} ; \mathrm{MgSO}_{4}, 200 \mu \mathrm{M} ; \mathrm{KCl}, 340 \mu \mathrm{M} ; \mathrm{FeSO}_{4}, 5 \mu \mathrm{M}$; $\left.\mathrm{MnSO}_{4}, 10 \mu \mathrm{M}\right)$. In the pulse experiment, $\mathrm{CdCl}_{2}$ was added to $10 \mu \mathrm{M}$ growth solution. After the $\mathrm{Cd}$ treatment, the plants were removed from the pot and washed thoroughly with fresh water. Tissues were collected and separated into roots, thick stalk, stem, and leaves before extraction. For large-scale isolation of the HMW complex from the roots, the water hyacinth was exposed to $10 \mu \mathrm{M} \mathrm{Cd}$ for 15 days and then subjected to the extraction procedure.

Extraction of Cd-Binding Complexes from Water Hyacinth. Sample tissue $(25 \mathrm{~g})$ was mixed with $100 \mathrm{~mL}$ of cold extraction buffer $(50 \mathrm{mM}$ Tris- $\mathrm{HCl}$ and $1 \%$ ascorbate, $\mathrm{pH} 8.0)$ and then homogenized at $4{ }^{\circ} \mathrm{C}$ by 10 repeated blending (high speed, $10 \mathrm{~s}$ ) and cooling (sitting on an ice bath for $50 \mathrm{~s}$ ). The homogenate was filtered through a fourlayer gauge, and the filtrate was clarified by centrifugation at $4{ }^{\circ} \mathrm{C}(40$ $\min , 25000 \mathrm{~g}$ ). This crude extract was dried by lyophilization and stored in a $-20^{\circ} \mathrm{C}$ freezer until use.

Purification of Cd-Binding Complexes. The Cd-binding complexes were separated by gel filtration on a Sephadex G-50 column $(1.6 \times 65 \mathrm{~cm})$ equilibrated with Tris- $\mathrm{HCl}$ buffer $(10 \mathrm{mM}, \mathrm{pH} 8.0$, containing $0.1 \mathrm{M} \mathrm{NaCl})$ in a cold room $(18,19)$. Crude extract $(2.4$ $\mathrm{mL}$ ) from water hyacinth was applied to the column and then eluted with the same buffer (flow rate $40 \mathrm{~mL} / \mathrm{h}$ ), and the eluent was collected $(2 \mathrm{~mL} /$ tube). Fractions were analyzed for $\mathrm{Cd}$ or protein content. The HMW complex was further purified by ion exchange (DEAE-Sephacel equilibrated in the same buffer, $2.6 \times 5 \mathrm{~cm}$ ). The complex was adsorbed on the gel and eluted by a linear $\mathrm{NaCl}$ gradient $(0.1-1.5 \mathrm{M}, 100 \mathrm{~mL}$ each).

Methods for Chemical Analysis. The protein content was determined by the dye-binding method (20) with the microassay system from Bio-Rad (protein assay kit). Bovine serum albumin was used as the standard. Cd was analyzed by atomic absorption spectrophotometry (Hitachi AAS 180-30). In the analysis based on dry weight, the tissue was dried to a constant weight at $80^{\circ} \mathrm{C}$ and then subjected to incineration at $600{ }^{\circ} \mathrm{C}$ and digestion with $6 \mathrm{~N} \mathrm{HCl}$. The thiol group was determined by reaction with Ellman's reagent and measurement of the absorbance at $410 \mathrm{~nm}(21)$. For the analysis of phytochelatins, samples were dissolved in $0.05 \%$ trifluoroacetic acid and then analyzed by reverse-phase HPLC (system, LC-9A, Shimadzu; column, Lichrospher 100RP-18, Merck) with a linear gradient of $0-20 \%$ acetonitrile. Each single PC peak was collected and identified by electron spray ionization mass spectrometry (ESIMS) from a commercial service.

Amino Acid Composition Analysis for Cd-Phytochelatin Complexes. Since phytochelatin contains only Glu, Cys, and Gly, it is convenient to identify $\mathrm{PC}$ by its amino acid composition. The ratio of Glu/Gly specifies the number $(n)$ of ( $\gamma$ Glu-Cys) repeats in PC structure, $(\gamma \text { Glu-Cys })_{n}$-Gly. The sample was dried completely in the test tube and then dissolved in $0.6 \mathrm{~mL}$ of hydrolysis solution ( $\mathrm{HCl}$ :trifluoroacetic acid $=4: 1$ ). The air in the test tube was removed by a suction pump, and then the tube was sealed carefully. It was then put into an oven 


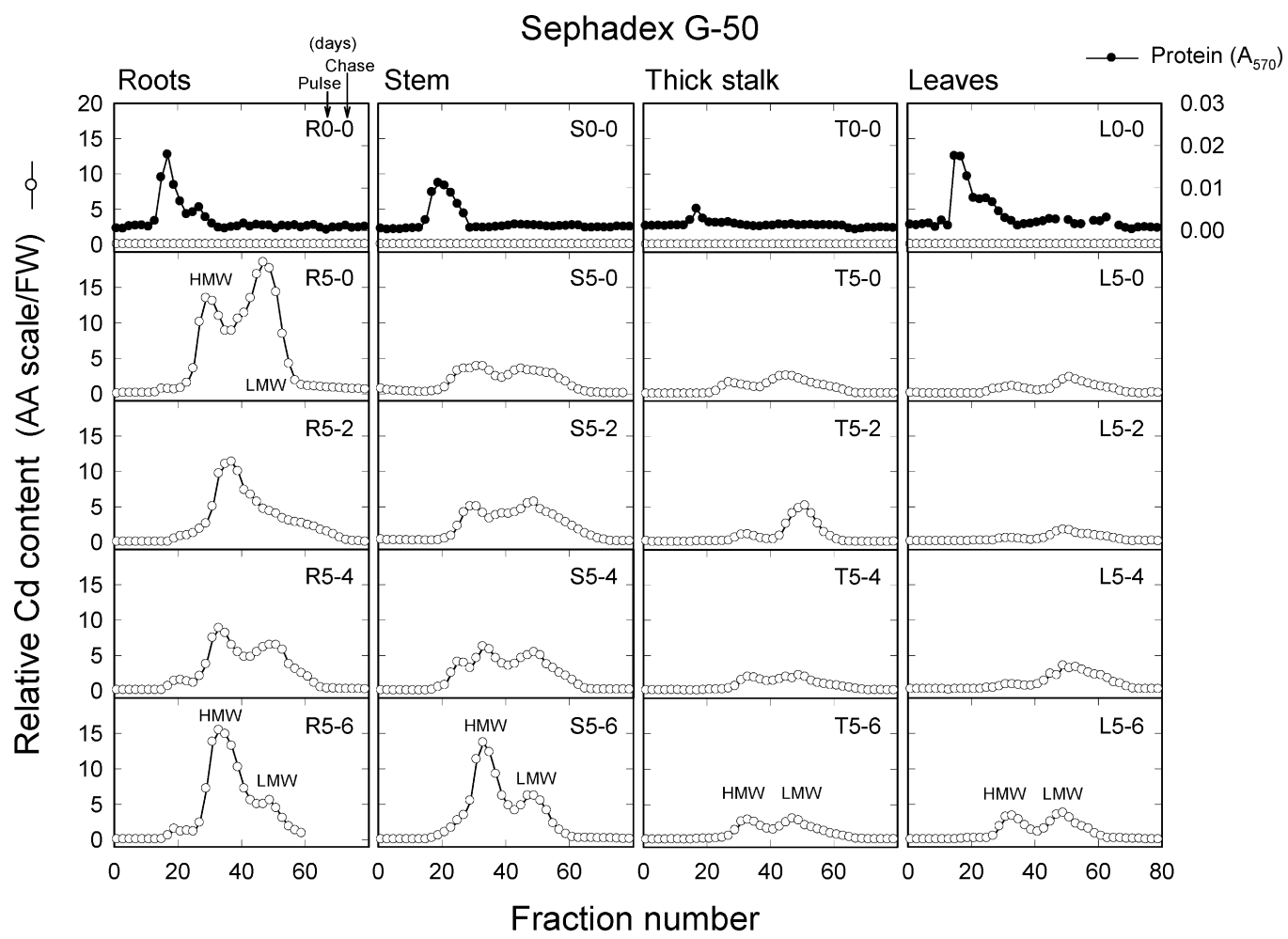

Figure 2. Water hyacinth was pulsed with $\mathrm{Cd}$ for 5 days and then chased in Cd-free solution as in Figure 1. The extracts from roots (R), stem (S), thick stalk $(T)$, and leaves $(L)$ were collected and subjected to gel filtration to reveal Cd-containing complexes (HMW and LMW).

and heated at $140{ }^{\circ} \mathrm{C}$ for $3 \mathrm{~h}$. The hydrolysate was dried by lyophilization and then analyzed by an amino acid analyzer (Beckman 6300).

\section{RESULTS}

Water Hyacinth Accumulated Cd Essentially in Its Roots, but a Fraction of the Cd Was Transported Upwardly. Water hyacinth was cultivated in the presence of $10 \mu \mathrm{M} \mathrm{Cd}$ for 5 days in the pulse period. After being washing with clean water thoroughly, the plants were transferred into the Cd-free solution and cultured for 1 week. Figure 1 shows that the concentration of $\mathrm{Cd}$ in the growth solution decreased rapidly during the first 2 days of pulse and then reached a concentration around 2 or 3 $\mu \mathrm{M}$ (Figure 1A). After changing to the Cd-free solution, the $\mathrm{Cd}$ concentration remained at $2 \mu \mathrm{M}$ throughout the whole chase period (Figure 1B). This observation indicates that water hyacinth could absorb up to $80 \%$ of the $\mathrm{Cd}$ in the growth solution and would not release much of the absorbed Cd back to the environment.

The Cd contents in the tissues of the pulse-chase-treated water hyacinth were further analyzed (Figure $\mathbf{1 C}-\mathbf{F})$. $\mathrm{Cd}$ was accumulated in the roots very rapidly once the water hyacinth was exposed to $\mathrm{Cd}$ but decreased when the plant was transferred to the Cd-free growth solution (Figure 1F). The decrease might be caused by the vigorous washing step between the pulse-chase treatments (indicated with a vertical dotted line in Figure 1). The stem had accumulated smaller amount of Cd (Figure 1E). Thick stalk is a swollen round-shaped organ that connects the stem and roots of water hyacinth. It is occupied by space and clear fluid, which makes the water hyacinth float on the surface of water. We cannot find significant amounts of $\mathrm{Cd}$ accumulated in thick stalk during the whole period (Figure 1D). However, $\mathrm{Cd}$ in the leaves began to appear after a longer incubation period (11 days in Figure 1C), which made up the amount of $\mathrm{Cd}$ that disappeared from the roots.
In order to monitor the distribution of Cd-binding complexes in the plant body, samples from roots, stem, thick stalk, and leaves during the chase periods were further analyzed by gel filtration on Sephadex G-50 (Figure 2). After 5 days of pulse, Cd-binding substances in the roots were distributed into two peaks, the LMW and HMW complexes (R5-0, 5 days pulse and 0 day chase). The LMW complex decreased rapidly during the chase period (R5-2 and R5-4), but the HMW complex kept increasing and became dominant (R5-6). Similarly, the stem accumulated both the HMW and LMW complexes but on a smaller scale (S5-0 through S5-6). Although thick stalk and leaves showed relatively low $\mathrm{Cd}$ content throughout the whole treatment, they eventually accumulated visible peaks of the two complexes (T5-6 and L5-6). In all cases, the LMW complex was produced prior to the HMW. In the final stages, both roots and stem accumulated the HMW complex as the major storage form.

Cd in the Roots Was Accumulated and Stored in the Form of HMW Complex. To further investigate the dynamic change of Cd-binding complexes, water hyacinth was grown continuously in Cd for 15 days (no chase), and the roots extract was analyzed by gel-filtration chromatography (Figure 3). There was no detectable $\mathrm{Cd}$ in the roots before $\mathrm{Cd}$ treatment (blank, Figure 3A). Since all samples revealed very similar elution patterns for the total proteins, only the blank protein profile is shown on the chromatogram, which consisted of a major peak eluted around the void volume. After 1 day of Cd treatment, the LMW peak containing $\mathrm{Cd}$ showed up (Figure 3B) and then decreased consistently in the following days. Since the LMW complex contained neither phytochelatin nor thiol compound (data not shown), it has not been investigated further in this study. On the other hand, after 5 days of incubation, the HMW peak emerged and then remained through the whole experiment (Figure 3C-E). This HMW peak was isolated and then subjected to further analysis as described below (Figure 4). The 


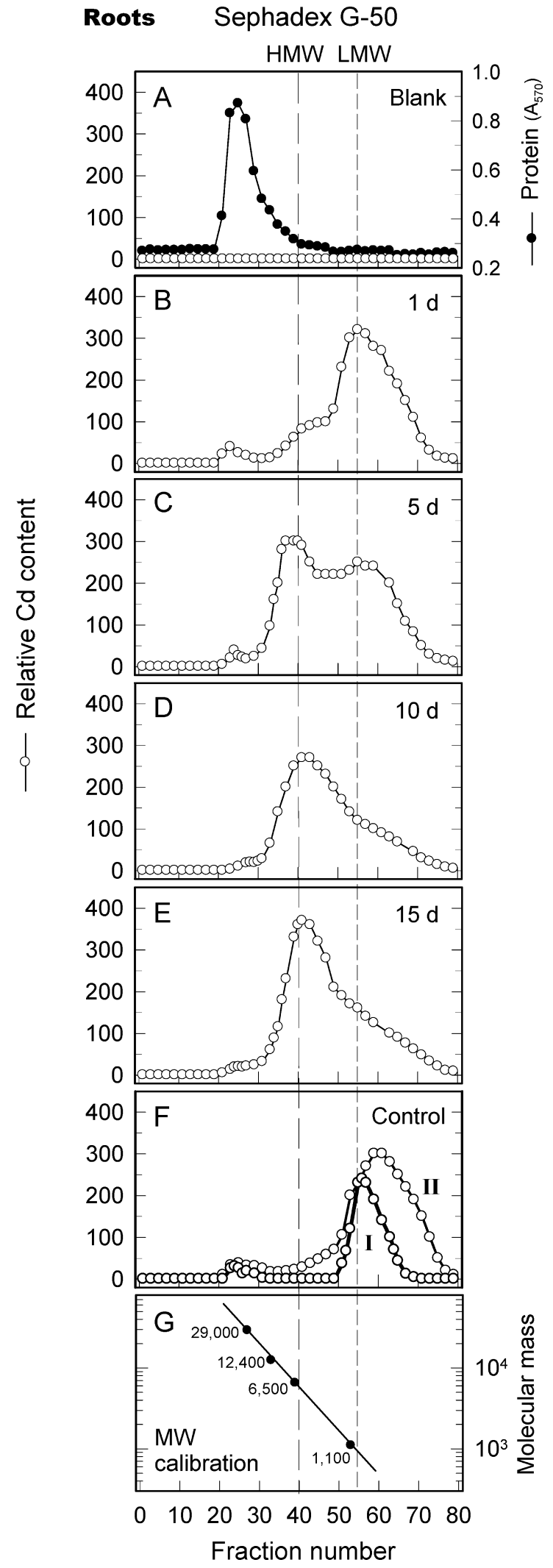

Figure 3. Water hyacinth was continuously cultivated in $10 \mu \mathrm{M}$ Cd solution for 15 days, and then its root extract was examined to show the change in $\mathbf{C d}$-containing complexes $(\mathbf{B}-\mathbf{E})$. Controls $(\mathbf{F})$ were performed by mixing the root extract of $\mathrm{Cd}$-free water hyacinth with $\mathrm{CdCl}_{2}$ before chromatography (peak I) or by immersing the roots of a fresh plant into the $\mathrm{Cd}$ solution briefly (5 s) and then washing and extracting immediately (peak II). (G) Molecular weight standards: carbonic anhydrase (29 000), cytochrome c (12 400), aprotinin (6500), and a synthetic peptide (1100). $\mathrm{FW}$, fresh weight of the plant. molecular mass of the HMW complex ranged from 5 to $8 \mathrm{kDa}$ as estimated from the calibration line (Figure 3G).

Two control experiments were designed to eliminate the possibility that these Cd-binding complexes were formed by nonspecific adsorption during the extraction procedure and not as a physiological response to the invading $\mathrm{Cd}$. First, the fresh extract of $\mathrm{Cd}$-free water hyacinth roots was added to $\mathrm{CdCl}_{2}$ before it was applied to the gel-filtration column. The major Cd peak appeared very late on the chromatogram near the LMW complex (peak I in Figure 3F). Second, a fresh Cd-free plant was immersed in Cd solution briefly (5 s) and then washed immediately; the crude extract of its roots was analyzed as well. The Cd peak appeared even later (peak II in Figure 3F), which corresponded to the elution volume of free $\mathrm{CdCl}_{2}$. Both control experiments showed no HMW complex on the chromatogram.

HMW Complex Composed of Phytochelatins and a Rare Derivative. The HMW complex collected from gel-filtration chromatography in Figure 3 was further purified by DEAE ion exchange (Figure 4A). A peak containing Cd, sulfhydryl group, and sulfide appeared when the column was eluted with a linear gradient of $\mathrm{NaCl}$. It was collected and analyzed by reversephase HPLC and was resolved into four major peaks (Figure 4B) that contained sulfhydryl compound (inset in Figure 4B). Peaks 1, 3, and 4 were identified as phytochelatins $\mathrm{PC}_{2}, \mathrm{PC}_{3}$, and $\mathrm{PC}_{4}$, respectively, by analysis of the amino acid composition (Table 1) and electron spray ionization-mass spectrometry (data not shown). The intensity of these peaks on the HPLC chromatogram revealed that the HMW complex consisted of mostly $\mathrm{PC}_{3}$ and $\mathrm{PC}_{4}$ and only a small amount of $\mathrm{PC}_{2}$.

Peak 2 showed a Glu/Gly ratio of 2.1, indicating it was related to $\mathrm{PC}_{2}$ in the basic structure. However, it contained a relative high percentage of Cys, and one additional Cys residue might be incorporated in the backbone of $\mathrm{PC}_{2}$ as estimated from its amino acid composition (Table 1). Indeed, when peak 2 was further analyzed by ESI-MS (Figure 4C), it revealed a signal at $m / z, 643$, corresponding to the molecular mass of the isoform Cys- $(\gamma \text { Glu-Cys })_{2}$-Gly, which might be derived from $\mathrm{PC}_{3}$ by removal of the N-terminal $\gamma$ Glu.

\section{DISCUSSION}

The pulse-chase experiment in this study showed that water hyacinth effectively accumulated $\mathrm{Cd}$ from the environment. Observations suggested that $\mathrm{Cd}$ was absorbed readily and stored in the roots, but a fraction was transported to the stem and to the leaves in 2 weeks. Once it entered the plant, the heavy metal was chelated by binding complexes and apparently would not be released back to the growth solution (Figure 1). This feature renders water hyacinth an ideal plant for the remediation of contaminated waters. Under our experimental conditions, the $\mathrm{Cd}$ concentration of growth solution was significantly reduced from $10 \mu \mathrm{M}$ to $2 \mu \mathrm{M}$ in 5 days. Cadmium was accumulated essentially in the roots, and a fraction of invading $\mathrm{Cd}$ was transported upwardly to the leaves through the stem. In total, the water hyacinth can absorb as much as $1 \mathrm{mg}$ of $\mathrm{Cd} / \mathrm{g}$ dry weight of the plant, which could be regarded as a high accumulator as compared to the normal composition of trace element in plants $(0.05 \mu \mathrm{g} / \mathrm{g}$ for $\mathrm{Cd})$ (22). The maximum absorption capacity depends on plants and the concentration of environmental heavy metals. When Thlaspi caerulescens is used as the hyperaccumulator, the roots accumulate as much as 4 $\mathrm{mg}$ of $\mathrm{Cd} / \mathrm{g}$ dry weight in $\mathrm{Cd}$ solutions up to $50 \mu \mathrm{M}$ (23). Notably, phytochelatin might not be responsible for Cd tolerance in T. caerulescens (23). Instead, Cys and other LMW thiols 

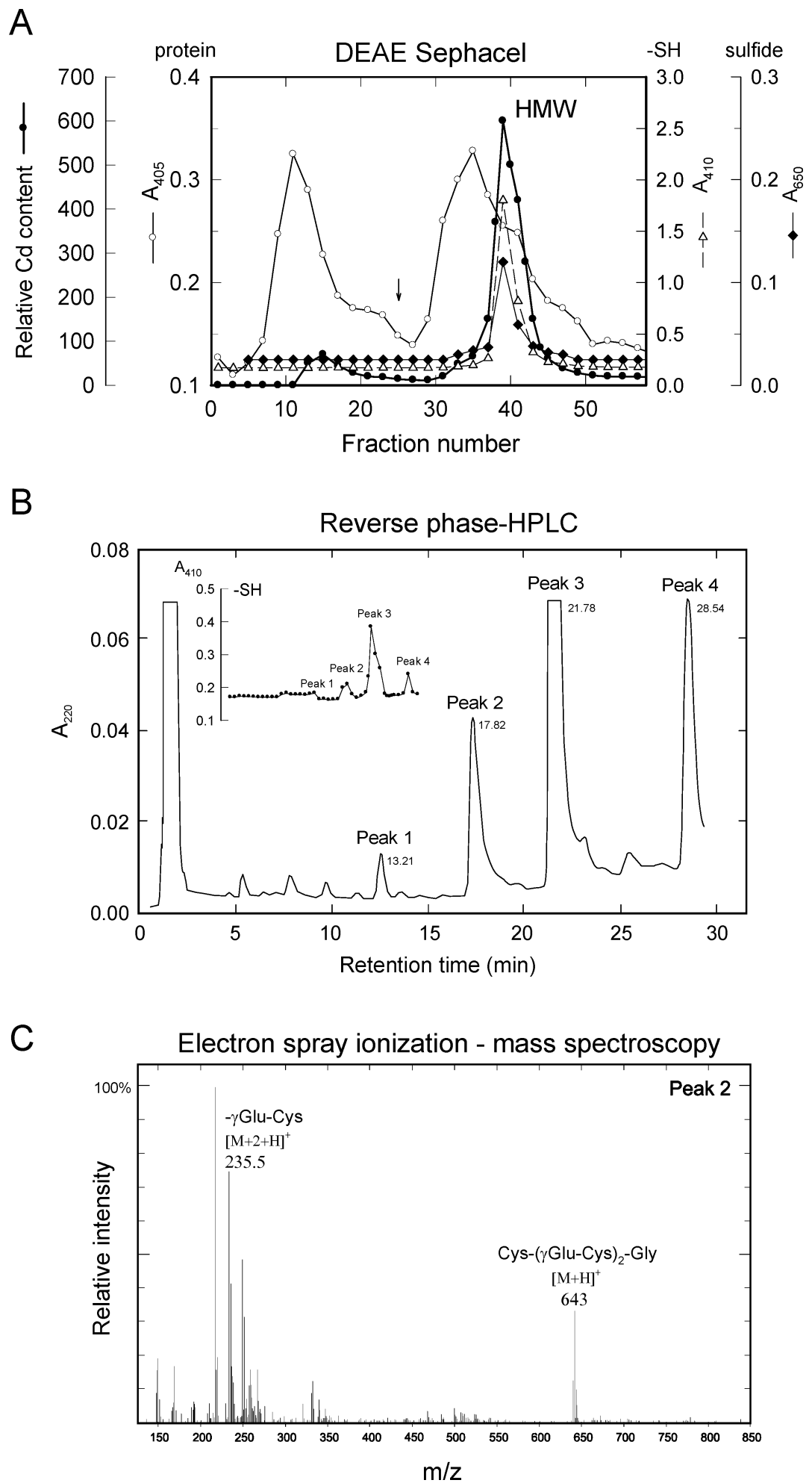

Figure 4. HMW complex in the roots isolated from gel filtration was further purified by ion exchange (A). A peak containing Cd, thio group, and sulfide was eluted by a linear $\mathrm{NaCl}$ gradient $(0.1-1.5 \mathrm{M}$, arrow marks the beginning of the gradient). It was further analyzed by reverse- phase HPLC (B), which revealed four peaks containing thiol group (inset in B). Peaks 1, 3, and 4 were identified as phytochelatins $\mathrm{PC}_{2}, \mathrm{PC}_{3}$, and $\mathrm{PC}_{4}$, respectively $($ Table 1). Peak 2 was further analyzed by ESI-MS (C) and showed fragments that might be derived from a PC-related peptide, Cys- $(\gamma \text { Glu-Cys })_{2}$-Gly $(\mathrm{m} / z=643)$.

might be involved (24). Interestingly, both LMW complexes found in $T$. caerulescens and water hyacinth seem different from the LMW from fission yeast in their composition. The LMW complex in fission yeast contains short PCs and is incorporated into HMW complex in the form of $\mathrm{CdS}$ and transported into the vacuole for storage $(8,25)$.
We examined the accumulation and distribution of HMW and LMW complexes in various tissues of water hyacinth after pulse with $\mathrm{Cd}$ (Figure 2). It is evident that the $\mathrm{Cd}$, or its complex form, was transported from the roots to the upper part of the plant. In roots, the LMW complex was produced very rapidly at the beginning and then disappeared gradually. Since the LMW 
Table 1. Amino Acid Compositions of Phytochelatins in the HMW Complex of Cd-Treated Water Hyacinth

\begin{tabular}{|c|c|c|c|c|}
\hline \multirow[b]{2}{*}{ amino acid } & \multicolumn{4}{|c|}{ percentage of amino acid residues } \\
\hline & peak 1 & peak 2 & peak 3 & peak 4 \\
\hline Asp & 1.1 & 1.2 & 1.8 & 1.6 \\
\hline Thr & 0.3 & 0.4 & 0.5 & 0.6 \\
\hline Ser & 1.0 & 0.7 & 1.6 & 1.2 \\
\hline Glu & 24.9 & 26.6 & 31.0 & 37.1 \\
\hline Pro & 0.1 & 0.0 & 0.1 & 0.2 \\
\hline Gly & 9.6 & 12.7 & 11.1 & 10.1 \\
\hline Ala & 0.5 & 1.0 & 0.9 & 1.3 \\
\hline Cys-Cys & 11.8 & 15.5 & 9.9 & 16.0 \\
\hline Val & 0.2 & 0.2 & 0.3 & 0.4 \\
\hline Met & 0.0 & 0.0 & 0.0 & 0.0 \\
\hline lle & 0.1 & 0.2 & 0.3 & 0.2 \\
\hline Leu & 0.3 & 0.3 & 0.4 & 0.4 \\
\hline Tyr & 0.1 & 0.0 & 0.0 & 0.0 \\
\hline Phe & 0.1 & 0.1 & 0.0 & 0.0 \\
\hline His & 0.1 & 0.1 & 0.2 & 0.3 \\
\hline Lys & 0.4 & 0.6 & 0.4 & 0.6 \\
\hline Arg & 0.2 & 0.1 & 0.2 & 0.3 \\
\hline Glu/Gly ratio & 2.6 & 2.1 & 2.8 & 3.7 \\
\hline $\begin{array}{l}\text { identified as } \\
\text { structure }\end{array}$ & $\begin{array}{l}P C_{2} \\
(\gamma \mathrm{E}-\mathrm{C})_{2}-\mathrm{G}\end{array}$ & $\begin{array}{l}P C \text { derivative } \\
\mathrm{C}-(\gamma \mathrm{E}-\mathrm{C})_{2}-\mathrm{G}\end{array}$ & $\begin{array}{l}P C_{3} \\
(\gamma \mathrm{E}-\mathrm{C})_{3}-\mathrm{G}\end{array}$ & $\begin{array}{l}P C_{4} \\
(\gamma \mathrm{E}-\mathrm{C})_{4}-\mathrm{G}\end{array}$ \\
\hline
\end{tabular}

complex from water hyacinth contained no phytochelatin, how Cd was bound to produce this LMW complex is not clear. Nevertheless, we assumed that the LMW complex in water hyacinth might serve as a transient form for prompt relief of the invading $\mathrm{Cd}$, which will be transformed into the stable HMW form eventually. Parallel to the accumulation of Cd (Figure 1), these two complexes appeared slowly in the upper part of the plant during later stages of the chase. Gong et al. (26) have shown that PCs can be transported from roots to shoots in a PC-deficient mutant of Arabidopsis that has been specifically transferred with a root-targeted PC synthase gene from wheat. Our results obtained from direct observations on water hyacinth are in agreement with their conclusions from the molecular genetic manipulations in the model plant. Recently, Chen et al. (27) also reported that PCs are transported over long distances from shoots to roots. However, the exact chemical structure for the $\mathrm{Cd}$ transportation from one tissue to another is still unclear. Since the LMW complex has a small molecular mass and could be converted into the HMW complex easily, it might be a possible candidate for the transportation. Besides, the dynamic changing patterns of the complexes (Figure 2) showed that all tissues accumulated the LMW complex at first and then gradually lost it in the later stages. This observation implied an "in-and-out" tendency for the LMW complex moving around the tissues. Nevertheless, the preliminary attempt to characterize the LMW complex on the basis of current knowledge was not successful in our laboratory. Together with the observations in T. caerulescens (24), it was suggested that the LWM complex might be produced through an unknown mechanism waiting to be discovered.

The HMW complex contained sulfide and phytochelatins, mostly $\mathrm{PC}_{3}$ (Figure 4B), in a composition very similar to the HMW complex found in fission yeast (8). Notably, water hyacinth produced only a small amount of $\mathrm{PC}_{2}$. Instead, a derivative of $\mathrm{PC}_{3}$ was found in which the N-terminal $\gamma$ Glu was lacking (Table 1 and Figure 4). Chassaigne et al. (28) have identified PC-related peptides in maize seedlings prepared enzymatically in vitro by mixing phytochelatin synthase with glutathione; they found $\gamma$ Glu-lacking phytochelatins in the reaction mixture. They proposed that these peptides might originate from enzymatic cleavage of $\gamma \mathrm{Glu}$. Apparently the $\mathrm{PC}_{3^{-}}$ related peptide in our study might be produced by a similar mechanism. However, the cleavage should be a natural process in water hyacinth but not an artificial in vitro reaction during the extraction procedure, since HMW is a stable sulfidecontaining complex that holds its PCs tightly (7), and any enzymatic modification or spatial rearrangement of its components will be relatively difficult. Furthermore, if any nonspecific enzyme did exist and catalyze the cleavage, then a mixture of $\gamma$ Glu-lacking $\mathrm{PC}_{2}, \mathrm{PC}_{3}$, and $\mathrm{PC}_{4}$ should be found. However, we could only detect the $\gamma$ Glu-lacking $\mathrm{PC}_{3}$ in the HPLC analysis (Figure 4B). This derivative contained an extra unit of Cys, which might enhance the binding capacity against $\mathrm{Cd}$ and contribute to the high heavy metal resistance of water hyacinth. The biosynthesis mechanism and the physiological significance of this isoform remain to be elucidated.

Putting all together, by tracing the absorption and sequestration of the pulsed $\mathrm{Cd}$ and the distribution patterns of the two complexes in various tissues, we concluded that water hyacinth is an efficient and reliable heavy metal accumulator in phytoremediation. It is reliable because water hyacinth will not release the absorbed $\mathrm{Cd}$ back to the environment but will store the invaded $\mathrm{Cd}$ in a stable HMW form of complex around its tissues.

\section{ACKNOWLEDGMENT}

We are grateful for the excellent technical assistance from the Technology Commons (TechComm), College of Life Science, National Taiwan University.

\section{LITERATURE CITED}

(1) Cobbett, C.; Goldsbrough, P. Phytochelatins and metallothioneins: Roles in heavy metal detoxification and homeostasis. Annu. Rev. Plant Biol. 2002, 53, 159-182.

(2) Hamer, D. H. Metallothionein. Annu. Rev. Biochem. 1986, 55, 913-951.

(3) Hayashi, Y.; Morikawa, S.; Kawabata, M.; Hotta, Y. The synthesis of cadystins, heavy metal chelating peptides, is induced in the fission yeast by wounds of the cell wall or by incubation with chitosan. Biochem. Biophys. Res. Commun. 1992, 188, 388-394.

(4) Grill, E.; Winnacker, E. L.; Zenk, M. H. Phytochelatins: the principal heavy-metal complexing peptides of higher plants. Science 1985, 230, 674-676.

(5) Rauser, W. E. Phytochelatins. Annu. Rev. Biochem. 1990, 59, 6186.

(6) Ortiz, D. F.; Kreppel, L.; Speiser, D. M.; Scheel, G.; McDonald, G.; Ow, D. W. Heavy metal tolerance in the fission yeast requires an ATP-binding cassette-type vacuolar membrane transporter. EMBO J. 1992, 11, 3491-3499.

(7) Reese, R. N.; Winge, D. R. Sulfide stabilization of the cadmiumgamma-glutamyl peptide complex of Schizosaccharomyces pombe. J. Biol. Chem. 1988, 263, 12832-12835.

(8) Wu, J. S.; Sung, H. Y.; Juang, R. H. Transformation of cadmiumbinding complexes during cadmium sequestration in fission yeast. Biochem. Mol. Biol. Int. 1995, 36, 1169-1175.

(9) Juang, R. H.; McCue, K. F.; Ow, D. W. Two purine biosynthetic enzymes that are required for cadmium tolerance in Schizosaccharomyces pombe utilize cysteine sulfinate in vitro. Arch. Biochem. Biophys. 1993, 304, 392-401.

(10) Clemens, S. Evolution and function of phytochelatin synthases. J. Plant Physiol. 2006, 163 (3), 319-332.

(11) Hirata, K.; Tsuji, N.; Miyamoto, K. Biosynthetic regulation of phytochelatins, heavy metal-binding peptides. J. Biosci. Bioeng. 2005, 100 (6), 593-599.

(12) Rea, P. A. Phytochelatin synthase, papain's cousin, in stereo. Proc. Natl. Acad. Sci. U.S.A 2006, 103 (3), 507-508.

(13) Gratao, P. L.; Polle, A.; Lea, P. J.; Azevedo, R. A. Making the life of heavy metal-stressed plants a little easier. Funct. Plant Biol. 2005, 32 (6), 481-494. 
(14) Cobbett, C. Heavy metals and plants - model systems and hyperaccumulators. New Phytol. 2003, 159 (2), 289-293.

(15) Malik, A. Environmental challenge vis a vis opportunity: The case of water hyacinth. Environ. Int.l 2007, 33 (1), 122-138.

(16) Ingole, N. W.; Bhole, A. G. Removal of heavy metals from aqueous solution by water hyacinth (Eichhornia crassipes). $J$. Water Supply: Res. Technol.-Aqua 2003, 52 (2), 119-128.

(17) Zhu, Y.; Zayed, A.; De-Souza, Q.; Terry, N. Phytoaccumulation of trace elements by wetland plants. II. Water hyacinth. J. Environ. Qual. 1999, 28, 339-344.

(18) Fujita, M. The presence of two Cd-binding components in the roots of water hyacinth cultivated in a $\mathrm{Cd}^{2+}$-containing medium. Plant Cell Physiol. 1985, 26, 295-300.

(19) Fujita, M.; Kawanishi, T. Purification and characterization of a Cd-binding complex from the root tissue of water hyacinth cultivated in a $\mathrm{Cd}^{2+}$-containing medium. Plant Cell Physiol. 1986, 27, 1317-1325.

(20) Bradford, M. M. A rapid and sensitive method for the quantitation of microgram quantities of protein utilizing the principle of protein-dye binding. Anal. Biochem. 1976, 72, 248-254.

(21) Ellman, G. L.; Courtney, K. D.; Andres, V.; Featherstone, R. M. A new and rapid colorimetric determination of acetylcholinesterase activity. Biochem. Pharmacol. 1961, 7, 88-95.

(22) Markert, B. Plants as biomonitors - Potential advantages and problems In Biogeochemistry of trace elements; Adriano, D. C., Chen, Z. S., Yang, S. S., Eds.;Science and Technology Letters: 1994; pp 601-613.
(23) Ebbs, S.; Lau, I.; Ahner, B.; Kochian, L. Phytochelatin synthesis is not responsible for $\mathrm{Cd}$ tolerance in the $\mathrm{Zn} / \mathrm{Cd}$ hyperaccumulator Thlaspi caerulescens (J. \& C. Presl). Planta 2002, 214 (4), 635640.

(24) Hernandez-Allica, J.; Garbisu, C.; Becerril, J. M.; Barrutia, O.; Garcia-Plazaola, J. I.; Zhao, F. J.; Mcgrath, S. P. Synthesis of low molecular weight thiols in response to Cd exposure in Thlaspi caerulescens. Plant Cell Environ. 2006, 29 (7), 1422-1429.

(25) Cobbett, C. S. Phytochelatins and their roles in heavy metal detoxification. Plant Physiol. 2000, 123, 825-832.

(26) Gong, J. M.; Lee, D. A.; Schroeder, J. I. Long-distance root-toshoot transport of phytochelatins and cadmium in Arabidopsis. Proc. Natl. Acad. Sci. USA 2003, 100 (17), 10118-10123.

(27) Chen, A.; Komives, E. A.; Schroeder, J. I. An improved grafting technique for mature Arabidopsis plants demonstrates longdistance shoot-to-root transport of phytochelatins in Arabidopsis. Plant Physiol. 2006, 141 (1), 108-120.

(28) Chassaigne, H.; Vacchina, V.; Kutchan, T. M.; Zenk, M. H. Identification of phytochelatin-related peptides in maize seedlings exposed to cadmium and obtained enzymatically in vitro. Phytochemistry 2001, 56, 657-668.

Received for review April 9, 2008. Revised manuscript received April 26, 2008. Accepted May 13, 2008. Part of this work was supported by the Council of Agriculture, ROC, Taiwan.

JF8011272 